\title{
ESTIMATING CROP COVER FRACTION FROM DIGITAL COLOR IMAGES
}

\author{
P. Karakus ${ }^{a *}$, H. Karabork ${ }^{b}$ \\ ${ }^{a}$ OKU, Engineering Faculty, Dept. of Geomatic Engineering 80000 Osmaniye, Turkey - pinarkarakus@ osmaniye.edu.tr \\ ${ }^{b}$ SU, Engineering Faculty, Dept. of Geomatic Engineering 42075 Konya, Turkey - karabork@ selcuk.edu.tr
}

KEY WORDS: Crop Cover Fraction, The Green Crop Tracker, RGB to HSI, Digital Camera, Object-Based Classification, Corn, Sunflower

\begin{abstract}
:
The use of automated methods to estimate crop cover fraction from digital color images has increased in recent years. Crop cover fraction can determine accurate, fast and inexpensive with this methods. A digital color images was acquired over each of the 30 sample fields in 2014 year at 2-3 week intervals. Study area has 15 sunflower fields and 15 corn fields. Digital color images were collected during 4 months, namely over the course of the growing season from sowing until harvesting to determine crop cover fraction. We used two approach to estimate crop cover fraction. In first method, the images were transformed from the RGB (red, green, blue) color space to the HSI (hue, intensity, saturation) color space. We used an object-based image analysis approach to classify the images into green vegetation and the other materials. In the second method, The Green Crop Tracker is less labor and time intensive than the objectbased classification approach, is a viable alternative to ground-based methods. By comparing object-based classification method and Green Crop Tracker software 2014 growing season, results were obtained: There were high correlations between the estimations obtained by object-based classification method and Green Crop Tracker software (for $2014 \mathrm{R}^{2}=0.89$ ). The relationship between two methods for 2014-23 sunflower field was calculated $\mathrm{R}^{2}=0.97$.
\end{abstract}

\section{INTRODUCTION}

Crop cover fraction is the vertical projection of the green vegetation (including leaves, stems, and branches) to the ground surface (Purevdorj et al., 1998). Image based methods have increased in recent years because digital color images can be acquired quickly, different times to assess for used this applications and images are easily archived.

The purpose of this study was to determine the feasibility of estimating crop cover fraction by digital camera images, which were taken vertically 1-1.5 m above the ground. Another purpose is to compare the two methods used to estimation of crop cover fraction.

\section{METHODS}

\subsection{Study area and in situ data measurement}

The study area is located in the east part of Mediterranean region, Osmaniye, Turkey. It is georaphically situated between $35^{\circ}$ and $36^{\circ}$ east longitudes and $36^{\circ}$ and $37^{\circ}$ north latitude. This area is very important region for agriculture because it has fertile soil.

To estimate crop cover fraction, a Sony DSC-S930 digital camera was used. A digital color images was acquired over each of the 30 sample fields 2014 year at 2-3 week intervals.

Digital color images for corn and sunflowers were collected during 2014 year, in the Kadirli of Osmaniye. Digital color photos were taken vertically from a height of 1-1.5 m.

\subsection{RGB to HSI}

RGB values can be converted directly to hue-saturation-intensity (HSI) values for ease of interpretation.

(Castleman, 1996) explained the conversion from RGB to HSI format can be performed as follows (Equ. 1.):

$H=\cos ^{-1}\left[\frac{(R-G)+(R-B)}{2 \sqrt{(R-G)^{2}+(R-B)(G-B)}}\right]$

$S=1-\frac{3 \times \min (R, G, B)}{R+G+B}$

$I=\frac{1}{3}(R+G+B)$

where $\mathrm{R}=\mathrm{Red}$

$\mathrm{G}=$ Green

$\mathrm{B}=\mathrm{Blue}$

represent the intensity levels recorded by the red, green and blue channels of the digital camera.

\subsection{Image Segmentation and analysis}

The digital camera images were imported into ecognition Developer software for processing. The digital color RGB image was converted to HSI color space. We classified green canopy and the other materials. The number of green pixels in each image was then divided by the total pixel count of the image for a determination of vegetation cover in the image. 


\subsection{Green Crop Tracker}

Green Crop Tracker is a histogram-based threshold method that was developed to differentiate gaps from plant tissues, in order to derive structural descriptors (Liu and Pattey, 2010; Liu and Pattey, 2013).

\section{RESULTS}

\subsection{Comparison of Green Crop Tracker and object-based classification}

The crop cover fraction derived from two methods. In the first method, the images were transformed from the RGB color space to the HSI color space, as is shown in Figure 1.

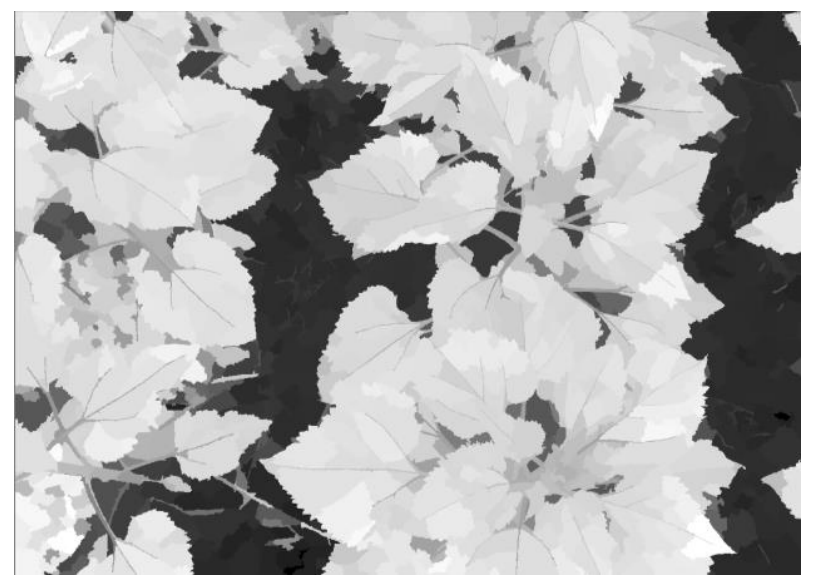

Figure 1. An example for digital camera images of 2014-23, sunflower plant images transformed RGB to HSI.

In the second part of the first method, an image is segmented into homogeneous areas with multiresolution segmentation. Then the number of green crop pixels in each image was then divided by the total pixel count of the image for a determination of vegetation cover in the image.

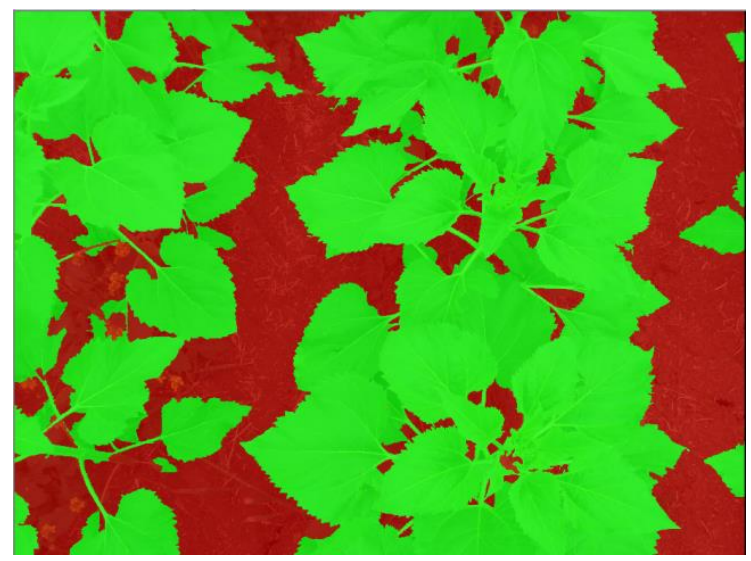

Figure 2. Digital camera images of 2014-23, sunflower plant image classified sunflower and the other materials.

In the second method, crop cover fraction estimated with green crop tracker software.
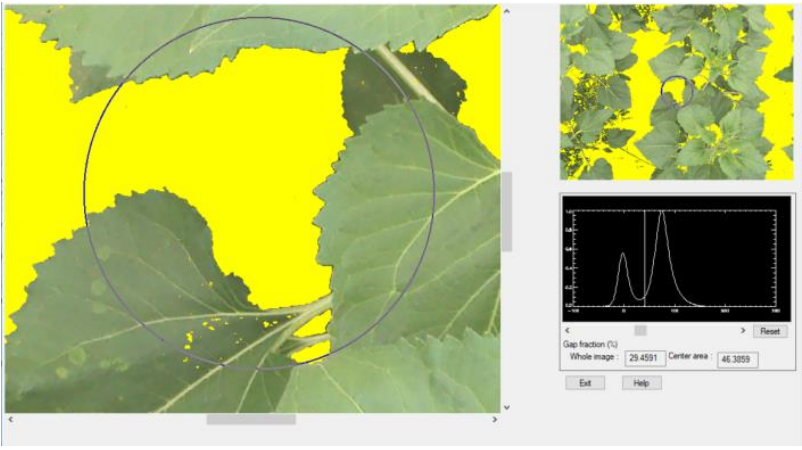

Figure 3. Digital camera images of 2014-23, sunflower plant image is classified by Green Crop Trcaker software.

Green Crop Tracker automatically derives estimates of green crop fraction. This software uses a histogram-based threshold method to estimate crop cover fraction.

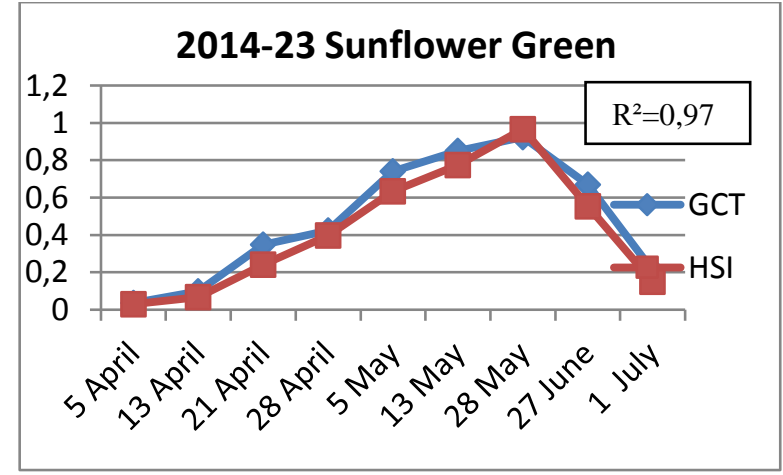

Figure 4. The relationship between two methods for 2014-23 sunflower field.

To explore the association between two methods throughout the season, $\mathrm{R}^{2}$ was used. There were high correlations between two methods, as is shown in Figure 4. When the relationship of 30 fields each other is examined, $\mathrm{R}^{2}=0,89$ determined.

\section{CONCLUSIONS AND DISCUSSION}

This study demonstrated a reliable, fast and cost effective way to estimate vegetation cover using digital camera images.Green Crop Tracker and an image-based approach using object-oriented classification from digital color images were an effective techniques for estimating fractional cover of vegetation and the other materials.

\section{REFERENCES}

Liu, J. G. and Pattey, E., 2010. Retrieval Of Leaf Area Index From Top-Of-Canopy Digital Photography Over Agricultural Crops. Agricultural and Forest Meteorology, 150, pp.1485-1490.

Liu, J., Pattey, E., and Admiral, S., 2013. Assessment of in situ crop LAI measurement using unidirectional view digital photography. Agric. Forest Meteorol., 169,pp.25-34.

Purevdorj, T., Tateishi, R., Ishiyama, T. and Honda, Y., 1998. Relationships between percent vegetation cover and vegetation indices. International Journal of Remote Sensing, 19 (18), pp.3519-3535. 